\section{P-162 RIGHT TIME, RIGHT PLACE, RIGHT PROFESSIONAL: A REVIEW OF COMMUNITY TEAM REFERRALS AND TRIAGE}

Claire Magee, Hazel Coop. Coventry and Warwickshire Partnership NHS Trust, Coventry, UK

10.1136/bmjspcare-2018-hospiceabs. 187

Background Referrals to the Coventry Community Palliative Care Team have increased over the last year, with a perceived increase in complexity. This has led to a waiting list and an increase in time to first contact for non-urgent referrals. The team instituted a quality improvement project to see if the responsiveness of the service could be improved, within the constraints of existing resources.

Methods PDSA (Plan, Do, Study, Act) methodology was used. A baseline review of all CNS referrals in December 2017 was conducted. A telephone triage tool and CNS triage rota were developed, along with a telephone triage caseload. A telephone call was made to the patient by an experienced CNS to allow a more robust and consistent assessment of the appropriateness and urgency of the referral. CNS referrals were analysed again in March 2018.

Results The new triage process improved efficiency. The existing process took up to nine days, with up to five documented contacts mainly from district nurses. In March 2018 84\% triage was performed with one contact; $26 \%$ patient, $36 \%$ relative, $10 \%$ nursing home staff, $21 \%$ other professionals. Only $47 \%$ patients triaged needed a face-to-face assessment, all of which were home visits. Non-urgent referrals previously waited up to 20 days to be seen. In March 2018 all referrals were seen within 10 days, with one exception seen at 15 days. All urgent referrals were seen within two days in both December 2017 and March 2018. The triage contact allowed the most appropriate multidisciplinary team member to see the patient.

Discussion A review in working practices has ensured patients are seen by the right professional in a timely manner, improving patient care. The new triage process has improved consistency and provides a more useful assessment of appropriateness and urgency, allowing care to be prioritised.

\section{P-163 MOTIVATION, COMMITMENT, CHALLENGE - EVOLVING A 24-HOUR ADVICE LINE TO A COMMUNITY RESPONSE SERVICE}

Gayle Roberts, Natalie Pepperall Wood, Wendy Gray, Jane Radnor Ortiz, Laura Wilson. St Margaret's Hospice, Taunton, UK

\subsection{6/bmjspcare-2018-hospiceabs. 188}

Background In line with national guidance and the 20152020 'Ambitions for Palliative and End of Life Care', the hospice developed a successful patient 24 hour advice line with an evolving county-wide community response service. This has involved reviewing the existing advice line service and resulted in expansion of the current team to ensure continuity and resilience within the service.

Aims Respond appropriately to patients, carers and health care professionals, advising on symptom control, providing reassurance, emotional and spiritual support. Enable the right care at the right time and in the right place. Reduce inappropriate hospital admissions.
Method Dedicated palliative care nurse telephone support and response triage. Governance, supervision and training in place with oversight by the line manager. Review of unmet need, plaudits and complaints - identify gaps.

Results

- Growing number of care homes utilising the service with reduced hospital admissions and described as a lifeline for patients and carers

- Promote and respect patients' preferred place of care through timely assessment and links with other out of hours services

- Review of hospice community nursing role out of hours and integrated working with other services.

Conclusion Using the advice line as a coordination hub, community hospice care will expand collaboratively with other services, sharing motivation and commitment to improve timely outcomes for patients in their preferred place of care and support to the wider care community.

\section{P-164 THE EVOLVEMENT OF A HOSPICE RESOURCE VEHICLE}

Jacqueline MCBlain. LOROS, Leicester, Great Britain

10.1136/bmjspcare-2018-hospiceabs. 189

Background At a senior management team away day in 2013, there was a discussion of three papers; 'Hospice and palliative care: access for all' (Help the Hospices, 2006), 'Dying for change' (Leadbeater \& Garber, 2010) and 'Future ambitions for hospice care: our mission and our opportunity' (Help the Hospices, 2013), with regards to how inequitable access to palliative care services can be. In order to reach the wider community who have limited awareness and access to hospice services, the idea of having a hospice resource vehicle, to engage with the public and professionals within Leicester, Leicestershire and Rutland was born.

Aims To purchase a bespoke vehicle and to increase face-toface contact through a range of clinical and information services. To deliver designated therapies within the resource vehicle at sites away from the hospice.

Methods October 2014 to July 2015 - visits to St Barnabas and St Giles Hospices to view their resource vehicles. April 2016 - Board agreement to purchase bespoke vehicle. April 2017 to April 2018 number of miles travelled, number of visits, recorded reads and number of enquiries.

Results January 2017 - receipt of bespoke vehicle named 'LOROS Local' assembled by Towmaster. April 2017 to April 20183500 miles travelled, 97 visits to 51 venues averaging three visits per week. 17023 recorded reads of external messages on the vehicle equalling 551 people enquiring about LOROS' services and a potential 79 volunteers recruited. May 2018 a weekly complementary therapy clinic hosted in the car-park of Green Towers leisure centre commenced with 41 treatments being delivered thus far.

Conclusion The most rewarding experiences have been those supportive conversations in which the team have been able to offer advice, support and signposting for members of the public who have sought advice. We will continue to develop the LOROS Local service through the community task and finish group. 


\section{P-165 THE DEVELOPMENT OF A MULTIDISCIPLINARY PALLIATIVE CARE OUTPATIENT CLINIC}

Anne Goggin, Kerry Worsfold, Fran Walton. Countess Mountbatten House, Southampton, UK

\subsection{6/bmjspcare-2018-hospiceabs.190}

Aim To develop a model of Palliative Care Outpatients that allows the patient access to appropriate professionals for their needs in a single visit.

Background There is good evidence that optimal palliative care of patients and their families is delivered through multidisciplinary teams. In 2015, to offer a more flexible and efficient service to our patients, we set up parallel medical and nursing outpatient clinics at the hospice. Our experience in running the outpatients and the identification of a need for therapy input led us to see the value of multidisciplinary consultations. We gained a place on our Trust's 'Team QI Fellowship Programme' which gave us a valuable framework for this new development.

Project design Adoption of the PDSA cycle (Plan, Do, Study, Act) model. Creation of a Driver Diagram to establish our overall goal and the steps we needed to complete to achieve the goal. Process mapping of current outpatient service. Development of a patient questionnaire. Feedback from staff delivering outpatients.

Findings

- Administration process lacked efficiency

- Admin team required further training

- Identified that additional admin resource needed to deliver the service efficiently

- Outpatient environment felt isolated

- Feedback from patients: outpatients is an acceptable and helpful environment for accessing specialist palliative care.

Actions Consultation with staff and volunteers to make changes to allow the MDT clinic to run alongside Drop-In service, creating a more welcoming environment for patients and carers. Accessed training for the admin team on the booking system and streamlined booking processes. Development of a business case for additional admin resource for outpatients.

Outcome We launched our new MDT clinic in February 2018. Results To date we have found our MDT clinic to be an effective way of delivering outpatient assessments.

Conclusion The patients have received a more holistic service in a single visit.

\section{P-166 VOLUNTEER HOME VISITING SERVICE}

Danielle Smeeton. LOROS Hospice, Leicester, UK

\subsection{6/bmjspcare-2018-hospiceabs.191}

Background Previously known as the Family Support Service, paid staff visited patients in their own homes to provide companionship, reduce social isolation and offer respite/a break to carers and families. This service was reviewed in 2013 and it was felt that although patients and carers found the service to be very beneficial, we remodelled the service so that it was less costly and could be offered to more patients, living at home. In 2014, the Home Visiting Service was launched as the remodelled Family Support Service. The Home Visiting Service provides volunteers to support patients and families in their own homes and the community.
Aims To give patients company, conversation and support in their own homes; and also the opportunity to go out and engage in community activities. The service can also benefit families and carers, to give them a break from their caring role, with peace of mind that their loved one is safe and occupied.

Methods High calibre volunteers are recruited and trained to visit patients in their own homes either weekly or fortnightly, for up to four hours (including travel). The volunteers can support patients by providing company and conversation but also assist with daily living, enabling patients to continue with their hobbies and can take patients out into the community.

Results 80 patients are currently being visited by 60 volunteers. Feedback from patients and families is very positive and some patients have said that the service is 'invaluable' and 'life altering'. The service has benefitted patients in the following ways: Reduced patients' social isolation; Enabled patients to play games/do quizzes/crosswords; Enabled patients to continue with hobbies; Enabled patients to get to appointments; Enabled patients to go out into the community to undertake physical exercise; Enabled patients, carers and families to have a break.

\section{P-167 TELEHEALTH PILOT: DEVELOPMENT AND SETTING UP OF A TELEHEALTH SERVICE FOR PALLIATIVE CARE PATIENTS}

1,2Emma Randall. 'Weldmar Hospicecare, Dorchester, UK; ${ }^{2}$ Macmillan, South West, UK

\subsection{6/bmjspcare-2018-hospiceabs.192}

Weldmar Hospicecare has growing numbers of patients being referred to the service who want to be supported in their own homes for as long as possible. Weldmar are working in partnership with Macmillan who are providing funding for an 18 month secondment post to set up and lead a telehealth pilot. Therefore enhancing the service offered to Weldmar patients and giving clinicians another tool to support and monitor patients. Telehealth is already being used in the UK for patients with long term conditions such as COPD and heart failure but there are limited numbers of palliative care patients using a telehealth service.

The pilot consists of a POD which has a protocol uploaded to it that has been written using recognised palliative care outcome measures; these are the Barthel Index and the IPOS scoring system. Patients $\log$ on daily completing the pre-set questions - this will monitor changes in symptoms and also level of need. The results are stored on the POD so clinicians visiting the home can access these, or have the option to access them remotely from their PC to review the data the patient has inputted.

The PODs have the capability for video-conferencing and allow clinicians to use this to discuss with patients the data they have inputted and also carry out assessments of patients face to face via Skype. Patients have embraced the pilot and use of the POD. They report the POD is quick and easy to use, they like that clinicians can monitor them remotely. Clinicians are adapting to having another tool to use to support patients and having access to a wealth of data about patients. Also having the ability to monitor changes in symptoms without being reliant on patients relaying to them how they have been over a set period of time. 